\title{
Parent Questionnaires in the Evaluation of Pre-School Children Referred for Neuropsychiatric Assessment
}

\author{
Mats Cederlund ${ }^{1,2}$ iD
}

Accepted: 9 May 2021 / Published online: 18 May 2021

(c) The Author(s) 2021

\begin{abstract}
One-hundred twenty-four pre-school children referred for assessment to a neuropsychiatric team were included in this study of the Autism Behavior Checklist (ABC), ESSENCE-Q, and Conners Abbreviated Parent-Teacher Rating Scale (CAPRS). All three questionnaires showed a good correlation towards severity of symptoms in ASD. The ABC questionnaire was, as has been shown in earlier research less accurate in identifying individuals with ASD having an IQ within the normal range. However the ESSENCE-Q, and the CAPRS proved to identify children with difficulties needing further assessment regardless of intellectual ability. The CAPRS showed a good correlation to severity in ASD indicating difficulties in the regulation of activity and behavior likely to be connected to ASD in pre-school children.
\end{abstract}

Keywords Autism behavior checklist $\cdot$ ESSENCE-Q $\cdot$ Conners abbreviated parent-teacher $\cdot$ Rating scale $\cdot$ Autism spectrum disorders · Pre-school children

\section{Introduction}

Autism spectrum disorder (ASD) is a neurodevelopmental disorder that has been estimated to affect 1-2 individuals in 100 according to previous research (e.g., Harrington \& Allen, 2014; Zablotsky et al., 2015). ASD has be found to be reliably diagnosed from 2 years of age, however the average age for a diagnosis of ASD ranges from 4 to 6 years worldwide (Mandell et al., 2010). Early detection of ASD has been proposed to improve outcome, and efforts have been undertaken to lower the age at which a diagnosis of ASD is made through screening, and broad-based developmental surveillance as well as ASD directed screening have been used (Broder-Fingert et al., 2018). Previous studies have shown that parents to children with ASD often identify a possible ASD in their child at an age as early as 12-18 months (De Giacomo \& Fombonne, 1998; Wimpory et al., 2000). However, their concern is often not taken seriously by Health care professionals (Ryan \& Salisbury, 2012). In addition,

Mats Cederlund

mats.cederlund@cereb.se

1 NU Hospital Organisation in Trollhättan, Trollhättan, Sweden

2 Cereb AB, Södergatan 11D, 25218 Helsingborg, Sweden once referred for neuropsychiatric assessment the children often end up in long waiting lists, which contributes to the delay in diagnosis (Zwaigenbaum, et al., 2016). Zwaigenbaum et al. (2016) showed in their study that children with more advanced language, better adaptive skills and/or milder ASD symptoms were likely to be overlooked by the screening at 18 months, and not diagnosed until approximately 3 years of age.

Over the last decades several screening instruments have been developed with the purpose of identifying children with suspected Autism Spectrum Disorders (ASD), and other neuropsychiatric/neurodevelopmental disorders in need of further assessment at an early age. Screening instruments are developed to facilitate the collection of information needed in the diagnostic process, when assessing a child with a suspected neuropsychiatric disorder, and not as diagnostic tools as such. When interpreting the information received from screening instruments the investigator must be aware of the difficulties the caregivers might experience in relating the specific items included in the questionnaires to their own child's real-life behaviors. In addition, symptoms related to ASD might be expressed differently depending on the respective child's specific verbal and non-verbal skills, and temperamental characteristics, which must also be taken into consideration, when interpreting the results from the questionnaires. Level-one screening instruments have been 
developed for the general (unselected) population, with the aim to identify children at risk of a developmental disorder. Level-two screening instruments have been developed to identify children at risk of ASD, who are already under the observation for developmental concerns, children who failed level-one screening or children that are siblings of children with a known ASD.

The Early Symptomatic Syndromes Eliciting Neurodevelopmental Clinical Examinations-Questionnaire(ESSENCE-Q), was developed by Professor Christopher Gillberg, at the Gillberg Neuropsychiatric Center (GNC) in Gothenburg, Sweden in 2010 (Gillberg, 2010). This levelone questionnaire was developed to highlight different psychiatric and learning problems experienced by children, particularly in the first 5 years of life, and to ensure that children, who present with early developmental problems are assessed for these impairments (Neville, 2013). The Conners Abbreviated Parent-Teacher Rating Scale (CAPRS), another level-one screening questionnaire, is an abbreviated version of the original Conners questionnaires for teachers and parents, respectively, addressing issues pertaining to difficulties in the regulation of activity, concentration, mood, and behavior, and was originally developed for the evaluation of symptoms related to Attention Deficit Hyperactivity Disorder (ADHD) (Conners, 1969).

The Autism Behavior Checklist (ABC) (Krug et al., 1980), which is a level-two screening questionnaire, focuses on the evaluation of autistic signs and symptoms present in an individual suspected of having an ASD. The ABC is easy to administer, and covers all main problematic areas included in ASD, albeit was originally developed for the assessment of autistic symptoms in individuals with moderate to severe intellectual disability, which might make it less assigned for children with near normal or normal intelligence. From earlier research it has been reported that children with an IQ above 70 tend to score below the cut-off proposed for the $\mathrm{ABC}$, making the authors dispute the diagnostic validity for the $\mathrm{ABC}$ in higher intellectually functioning individuals (Volkmar et al., 1988; Wadden et al., 1991). However, in their study Volkmar et al. (1988) found a good correlation across $\mathrm{ABC}$ scores and the Vineland Adaptive Behavior Scales, except for the scores related to language (Volkmar et al., 1988).

In this study the author decided to use these three individually quite different questionnaires in order to evaluate different problems present in pre-school children referred for neuropsychiatric assessment. The ESSENCE-Q, which is the most recently developed questionnaire of the questionnaires used, was selected because it has a broader approach addressing neurodevelopmental as well as neuropsychiatric problems, including issues covering, for example, inattention, communication, social interaction, sleep, and feeding problems. The CAPRS was chosen to assess the presence of more "typical" ADHD symptoms such as hyperactivity, difficulties with concentration, impulsivity, mood, and behavior in this group of pre-school children referred for neuropsychiatric assessment, in place of larger and more complex questionnaires primarily developed for the assessment of school children. Finally, the ABC was chosen to evaluate the usefulness of this questionnaire, originally developed to evaluate autistic symptoms and signs in children with moderate to severe intellectual disability, in this group of presumably less intellectually affected pre-school children.

To create a solid base for the gathering of relevant information for the diagnostic process the Diagnostic Interview for Social and Communication Disorders-Eleventh Edition (DISCO-11) was used (Wing, 2006; Wing et al., 2002). In this semi-quantitative instrument information retrieved from the parent(s)/caregiver(s) is combined with the investigating professional's view of the child. The DISCO-11 was chosen in favor of the Autism Diagnostic Interview-Revised (ADIR) (Lord et al. (1994) since the DISCO-11, in addition to the large number of items addressing autistic symptoms and signs also has a developmental perspective. Furthermore, these semi-quantitative instruments have shown excellent overall agreement according to the Landis and Koch criteria in earlier research (Landis \& Koch, 1977; Nygren et al., 2009).

The primary aim of this study was to assess the $\mathrm{ABC}$, the ESSENCE-Q, and the CAPRS, towards the International Statistical Classification of Diseases and Related Health Problems- 10th revision (ICD-10) ASD diagnoses (World Health Organization (WHO), 1992).

\section{Materials and Methods}

\section{Participants}

All the parent(s)/caregiver(s) of the pre-school children referred consecutively for neuropsychiatric assessment to the Child- and adolescent clinic at the NU Hospital, in Trollhättan, Sweden, from April 2014 to June 2016, were invited by letter to take part in the present study if they knew Swedish well enough to be able to perform the DISCO-11 interview without an interpreter present. Both parents had to sign the consent to take part in the study if custody over the child was shared. All in all, $126(69 \%)$ of the 182 children invited for inclusion in the study agreed to participate. For demographic information concerning the participating children please see Table 1.

\section{Procedure}

The DISCO-11 was completed in 124 individuals (98\%). In two children the DISCO-11 interview was not performed 
Table 1 Demographic data concerning all children included in the study $(\mathrm{n}=126)$

\begin{tabular}{|c|c|c|c|c|}
\hline & All children $(n=126)$ & $\begin{array}{l}\text { ICD-10 Autism } \\
(\mathrm{n}=89)\end{array}$ & $\begin{array}{l}\text { ICD-10 Atypical autism/ } \\
\text { AS }(n=17)\end{array}$ & $\begin{array}{l}\text { No ICD-10 } \\
\operatorname{ASD}(\mathrm{n}=18)\end{array}$ \\
\hline Girls (\%) & $30(23.8)$ & $19(15.1)$ & $6(4.8)$ & $5(4.0)$ \\
\hline Boys $(\%)^{*} / * *$ & $96(76.2)$ & $70(55.6)$ & $11(8.7)$ & $13(10.3)$ \\
\hline $\begin{array}{l}\text { Mean age all participants in in months } \\
\text { (SD) }\end{array}$ & $54.4(15.8)$ & $53.8(16.1)$ & $53.4(15.8)$ & $57.2(14.6)$ \\
\hline Median (min; max) & $55(11 ; 94)$ & $56(11 ; 94)$ & $48(30 ; 83)$ & $56(24 ; 85)$ \\
\hline Mean age girls in months (SD) & $50.9(15.4)$ & $51.6(15.8)$ & $48.8(15.3)$ & $51(17.2)$ \\
\hline Median (min; max) & $54.5(24 ; 74)$ & $56(28 ; 73)$ & $53(30 ; 74)$ & $55(24 ; 71)$ \\
\hline Mean age boys in months (SD) & $55.4(15.8)$ & $54.3(16.2)$ & $55.8(15.7)$ & $59.5(13.4)$ \\
\hline Median (min; max) & $56(11 ; 94)$ & $55.5(11 ; 94)$ & $48(36 ; 83)$ & $59(35 ; 85)$ \\
\hline Born in Sweden $(\%)^{* / * *}$ & $119(94.4)$ & $83(69.7)$ & $16(13.4)$ & $18(15.1)$ \\
\hline Born abroad (\%) & $7(5.6)$ & $6(4.8)$ & $1(0.8)$ & $0(0)$ \\
\hline Prematurely born girls (\%) & $4(13.3)$ & $3(10.0)$ & $0(0)$ & $1(3.3)$ \\
\hline Prematurely born boys $(\%)^{*}$ & $8(8.3)$ & $5(5.2)$ & $2(2.1)$ & $0(0)$ \\
\hline
\end{tabular}

* One prematurely born boy was not diagnosed due to discontinuation of the study

** One boy born at term was not diagnosed due to discontinuation of the study

because of discontinuation of the study. Despite the original exclusion criteria, one of the DISCO-11-interviews had to be made with an interpreter present because after the child was included in the study the parents were found not to master the Swedish language sufficiently for an independent interview.

At the DISCO-11-interview the ABC, the ESSENCE-Q, and the CAPRS were distributed to the parent(s)/caregiver(s) for completion after the investigator had explained to them how to respond to the questionnaires. At the end of the meeting the questionnaires were returned to the investigator.

At the DISCO-11 interview the Vineland-II Parent/ caregiver Rating Form was distributed to the parent(s)/ caregiver(s) along with a prepaid envelope to be returned to the investigator. The Vineland II Rating Form, which was chosen instead of the Vineland-II Survey Interview Form due to limited time for the investigator for the performance of the study, was distributed to all but three individuals. Two children were $<24$ months of age, and below the age at which the Vineland-II Parent/Caregiver Rating Form, Swedish version, was validated, and the third case concerned the parents mentioned above, who did not to know enough Swedish to complete the Vineland-II Survey Interview Form by themselves. All in all, $117(97 \%)$ of the 121 distributed Vineland-II Survey Interview Forms were returned.

The investigating author, who performed all the 124 DISCO-11-interviews, was trained on the DISCO-11 by Lorna Wing and Judith Gould, and has used the DISCO-11 for several years in research as well as in clinical work. In addition, the investigator has been proven to possess scoring ability on the DISCO-11 equivalent to the investigators responsible for the Swedish version of DISCO-11 at the GNC in Gothenburg Sweden.

\section{Psychological Evaluation}

Psychological assessment was performed in 112 children, and 89 of these individuals were tested with one of the Wechsler scales (i.e. Wechsler Preschool and Primary Scale of Intelligence-Third Edition (WPPSI-III, Wechsler, 2002) $(n=24)$, Wechsler Preschool and Primary Scale of Intelligence-Fourth Edition (WPPSI-IV, Wechsler, 2012) $(n=55)$, Wechsler Intelligence Scale for Children-Fourth Edition (WISC-IV, Wechsler, 2003) $(\mathrm{n}=5)$, or Wechsler Nonverbal Scale of Ability (WNV, Wechsler \& Naglieri, 2006) $(n=5)$. For the remaining 6 individuals either the Merrill-PalmerR, (Roid \& Sampers, 2000) $(n=4)$, or the Bayley Scales of Toddler Development-Third Edition, (Bayley, 2006) $(n=2)$ was used. The 17 individuals, who were assessed by a psychologist, albeit where no intelligence/developmental test was possible to perform, and the additional twelve individuals, who were not assessed by a psychologist, all had their developmental/intellectual level determined by their presentation at the visit to the clinic, and the information concerning developmental abilities acquired from the DISCO-11 interview.

Concerning intellectual ability, the participating children were organized according to the intellectual ability grading system presented in the DISCO-11: (1) Profound intellectual disability (IQ 0-19), (2) Severe intellectual disability (IQ 20-34), (3) Moderate intellectual disability (IQ 35-49), (4) Mild intellectual disability (IQ 50-69), (5) Intelligence 
below average (IQ 70-89), (6) Average intelligence (IQ 90-119, (7) Intelligence above average (IQ > 120).

\section{Expressive Language Level}

The respective child's expressive language ability was scored according to information received from the parent(s)/ caregiver(s), and from the child's presentation at the visit to the clinic using the following scheme: Nonverbal, Single words, Phrases, Undeveloped sentences, and Adequate speech.

\section{Instruments Included in the Study}

\section{Diagnostic Interview for Social and Communicative Disorders (DISCO-11)}

The DISCO-11 is a semi-structured interview intended for interview with a parent/caregiver, who knows the child well. The DISCO-11 includes a range of items with the intention to detect also milder forms of ASD, and it has been proven to be highly valid for assigning diagnoses in the autism spectrum. In addition, it has a developmental perspective and is designed for use from early childhood (Maljars et al., 2012; Nygren et al., 2009; Wing et al., 2002).

\section{Autism Behavior Checklist (ABC)}

The ABC was developed by Krug et al. (1980), and describes a series of typical autistic behaviors, and aims to assess the presence of these behaviors in a certain subject. The assessment form consists in 57 items, each of which corresponds to a single score referring to an area of symptoms. Five areas are considered in the original $\mathrm{ABC}$ questionnaire: sensory (9 items), relating (12 items), stereotypes and object use (12 items), language (13 items), and self-help and social (11 items). The total score is obtained by adding the scores from the different areas. The items are dichotomous (yes/ no), albeit they are assigned weights from 1 to $4 p$ according to their importance for the diagnosis at the original chisquare analyses at the validation of the questionnaire. The maximum possible score is $158 \mathrm{p}$. According to the original validation a score $\geq 67 p$ is strongly indicative of autism; a score between 53 and 66p indicates a moderate probability of autism; a score between 47 and 52p is considered inconclusive for a diagnosis of autism, and a score below $47 \mathrm{p}$ is to be considered as non-autistic. In contrast, Nordin and Gillberg (1996) found a score $\geq 45 p$ to be indicative of autism, and Fernell et al. (2010) reported that even scores below 45p would have to be considered as indicative of autism in very young children without speech.
Early Symptomatic Syndromes Eliciting Neurodevelopmental Clinical Examinations-Questionnaire (ESSENCE-Q)

A 12-item level-one questionnaire developed for screening purposes in children in Child Care Centers, as a screening tool of neurodevelopmental disorders or as a parent questionnaire in clinical settings, which contains items concerning the child's (1) General development, (2) Motor development, (3) Reaction to sensory stimuli, (4) Communicative ability, (5) Activity, (6) Attention, (7) Social interaction, (8) Behavior, (9) Mood, (10) Sleep, (11) Feeding, and, the presence of (12) Absences ("Funny spells"). Each item is scored Yes, Maybe/a little, or No, which translates to 2, 1, and 0p, respectively. The cut-off level for the ESSENCE-Q has been proposed to lay at $\geq 3 \mathrm{p}$, which gained a sensitivity rate of 0.87 , and a specificity rate of 0.77 in the validating study by Hatakenaka et al. (2016), and in a more recent clinic-based European multicenter study the authors found a sensitivity rate of 0.96 , and specificity rate of 0.84 , using the same cutoff score (Stevanovic, et al., 2018).

\section{Conners Abbreviated Parent-Teacher Rating Scale (CAPRS)}

A 10 item level-one questionnaire based on the 10 most often checked items in the Conners 39 items teacher questionnaire, and the Connners 93 items parent questionnaire (Conners, 1969), in which the child's behavior concerning the following aspects are scored: (1) Restless or overactive, (2) Excitable, impulsive, (3) Disturbs other children, (4) Fails to finish things started - short attention span, (5) Constantly fidgeting, (6) Inattentive, easily distracted, (7) Demands must be met immediately, easily frustrated, (8) Cries often and easily, (9) Mood changes quickly, and drastically, and (10) Temper outbursts, explosive and unpredictable behavior. The items are scored on a four graded Likert-scale: $0 \mathrm{p}-$ Not true at all/never, $1 \mathrm{p}$ - Just a little, $2 \mathrm{p}$-Quite a bit, $3 \mathrm{p}$-Very much true/very frequently. The original cut-off level presented by Conners was $15 p$ (or a mean item score of $\geq 1.5 p$ ), above which a clinically significant hyperactivity was likely to be present (Rowe \& Rowe, 1997). In a study of pre-school children by Kadesjö et al. (2001), the CAPRS was found to produce significant difference across a group of children with ADHD, and a control group of typically developing children.

\section{Vineland Adaptive Behavior Scales- II Parent/Caregiver Rating Form}

A Parent/Caregiver Rating Questionnaire, which offers a comprehensive assessment of adaptive behavior. It covers three major areas (1) Communication (2) Daily Living Skills, an (3) Socialization, and in addition a Motor Skills domain is included. From the scores of these scales 
a General Adaptive Functioning (GAF) Skills score can be derived (Sparrow et al., 2005).

\section{Statistical Methods}

Descriptive statistics are presented as mean, standard deviation, median, minimum and maximum for continuous variables and as numbers and percentages for categorical variables. For comparison between two groups the Student two-sample T-test was used for continuous variables. Effect sizes were calculated for the total scores of all the used questionnaires across the diagnostic groups. The Spearman correlation coefficient was used for the comparison of the items of the respective questionnaires. All significance tests were two-sided and conducted at the 5\% significance level.

\section{Results}

\section{ABC, ESSENCE-Q, and CAPRS Total Scores}

When the participating children were collapsed into groups based on the respective ICD-10 ASD diagnoses/No ICD10 ASD diagnosis they acquired after the assessment, all three screening instruments used were found to have a significant correlation towards severity of the ASD, with the highest mean scores for the group of children with ICD-10 Autism, and the lowest mean scores for the No ICD-10 ASD diagnosis group. The $\mathrm{ABC}$ had the strongest. correlation $\left(r_{s} 0.630\right)$, and the CAPRS had the weakest correlation ( $r_{s}$ $0.379)$. However, all the assessed questionnaires showed a significant correlation representing a $p$ level of $<0.001$. In addition, correlation across the assessed questionnaires was good: ABC versus ESSENCE-Q $\left(r_{s} 0.698, p<0.001\right)$, ABC versus CAPRS $\left(\mathrm{r}_{\mathrm{s}} 0.579, \mathrm{p}<0.001\right)$, and CAPRS versus ESSENCE-Q $\left(r_{s} 0.625, p<0.001\right)$. The results of the effect sizes for the total scores of the used questionnaires across the ICD-10 ASD diagnostic groups are presented in Table 2.

\section{ABC Total Score and Subscores}

Twenty-five out of the 89 individuals (28.1\%) diagnosed with ICD-10 Autism scored $\geq 67 \mathrm{p}, 18$ out of the 89 individuals $(20.2 \%)$ scored between 53 and 66p, and 8 out of the 89 individuals $(9.0 \%)$ scored between 47 and 52p. Thus $57.3 \%$ of the individuals diagnosed with ICD-10 Autism scored positive or inconclusive on the $\mathrm{ABC}$ if the originally presented cut-off scores of the questionnaire were used. If the cut-off of $\geq 45 p$ proposed by Nordin and Gillberg (1996) was used 54 individuals $(60.7 \%)$ scored above cut-off.

All the ABC subscores, representing the sub-areas sensory reactions, relating, stereotypes and object use, language, and self-help and social, were significantly correlated $(\mathrm{p}<0.001)$ to the severity of the ICD-10 ASD diagnoses (Table 3).

\section{ESSENCE-Q Total Score and Item Scores}

All individuals in this study, except three, who received an ICD-10 Autism diagnosis, scored above the cut-off score for ESSENCE-Q of $\geq 3 p$ as proposed by Hatanaka et al. (2016), indicating a need for further neuropsychiatric/neurodevelopmental assessment.

The vast majority, 9 of the 12 items included in the ESSENCE-Q, had a significant correlation to ICD-10 ASD severity, with a correlation at the $\mathrm{p}<0.001$ level for six of the twelve items (i.e., Social interaction, General development, Attention, Sensory reactions, Behavior, and Feeding). However, the items Communication, Sleep, and Absences failed to produce significant differences across the ICD-10 ASD/No ICD-10 ASD groups (Table 4).

Table 2 Effect sizes for the different questionnaires across the ICD-10 ASD diagnostic groups

\begin{tabular}{|c|c|c|c|c|c|c|}
\hline $\begin{array}{l}\text { Variable/ICD-10 } \\
\text { ASD diagnoses }\end{array}$ & $\begin{array}{l}\text { ICD-10 autism } \\
\mathrm{n}=89\end{array}$ & $\begin{array}{l}\text { ICD-10 atypical } \\
\text { autism/AS } n=17\end{array}$ & $\begin{array}{l}\text { No ICD-10 ASD } \\
\mathrm{n}=18\end{array}$ & $\begin{array}{l}\text { ICD-10 autism vs } \\
\text { ICD-10 AA/AS } \\
\text { effect size }\end{array}$ & $\begin{array}{l}\text { ICD-10 autism vs } \\
\text { No ICD-10 ASD } \\
\text { effect size }\end{array}$ & $\begin{array}{l}\text { ICD-10 AA/AS vs } \\
\text { No ICD-10 ASD } \\
\text { effect size }\end{array}$ \\
\hline \multirow[t]{2}{*}{$\mathrm{ABC}$} & $51.4(22.6)$ & $26,1(13.5)$ & $13.4(8.9)$ & 1.18 & 1.81 & 1.11 \\
\hline & $51(7 ; 108)$ & $22(10 ; 48)$ & $9.5(2 ; 29)$ & & & \\
\hline \multirow[t]{2}{*}{ ESSENCE-Q } & $11.4(4.9)$ & $6.6(3.0)$ & $4.8(3.2)$ & 1.02 & 1.41 & 0.605 \\
\hline & $11(2 ; 21)$ & $6(2 ; 12)$ & $4(2 ; 13)$ & & & \\
\hline \multirow[t]{2}{*}{ Conners } & $13.8(8.6)$ & $8.5(6.4)$ & $6.0(7.5)$ & 0.647 & 0.930 & 0.355 \\
\hline & $13(0 ; 30)$ & $7(0 ; 23)$ & $2.5(0 ; 23)$ & & & \\
\hline \multirow[t]{3}{*}{ Vineland II GAF } & $66.5(13.4)$ & $73.7(15.8)$ & 84.5 (13.6) & -0.517 & -1.34 & -0.739 \\
\hline & $65(45 ; 105)$ & $70.5(48 ; 106)$ & $86(61 ; 120)$ & & & \\
\hline & $\mathrm{n}=84$ & $\mathrm{n}=16$ & $\mathrm{n}=17$ & & & \\
\hline
\end{tabular}


Table $3 \mathrm{ABC}$ total score, and subscores, in relation to ICD-10 ASD diagnoses

\begin{tabular}{|c|c|c|c|c|}
\hline $\mathrm{ABC}$ items/Diagnosis & ICD-10 autism $n=89$ & $\begin{array}{l}\text { ICD-10 atypical autism/ } \\
\text { AS } n=17\end{array}$ & $\begin{array}{l}\text { No ICD-10 ASD diag- } \\
\text { nosis } n=18\end{array}$ & $\begin{array}{l}\text { Spearman correla- } \\
\text { tion coefficient } \& \text { p } \\
\text { value }\end{array}$ \\
\hline \multirow[t]{2}{*}{ Total score mean (SD) } & $51.4(22.6)$ & $26.1(13.5)$ & $13.4(8.9)$ & $\mathrm{r}_{\mathrm{s}} 0.630$ \\
\hline & $51(7 ; 108)$ & $22(10 ; 48)$ & $9.5(2 ; 29)$ & $\mathrm{p}<0.001$ \\
\hline \multirow[t]{2}{*}{ Sensory (SD) } & $6.8(4.0)$ & $2.9(3.1)$ & $3.0(2.8)$ & $r_{s} 0.433$ \\
\hline & $7(0 ; 17)$ & $3(0 ; 10)$ & $3(0 ; 7)$ & $\mathrm{P}<0.001$ \\
\hline \multirow[t]{2}{*}{ Social interaction (SD) } & $13.0(7.6)$ & $7.5(6.5)$ & $2.3(4.1)$ & $\mathrm{r}_{\mathrm{s}} 0.499$ \\
\hline & $14(0 ; 31)$ & $7(0 ; 26)$ & $0(0 ; 15)$ & $\mathrm{P}<0.001$ \\
\hline \multirow[t]{2}{*}{ Body (SD) } & $15.5(8.6)$ & $5.8(4.5)$ & $4.4(3.9)$ & $\mathrm{r}_{\mathrm{s}} 0.553$ \\
\hline & $15(0 ; 34)$ & $7(0 ; 11)$ & $4(0 ; 11)$ & $\mathrm{p}<0.001$ \\
\hline \multirow[t]{2}{*}{ Language/communication (SD) } & $6.4(4.6)$ & $4.6(3.6)$ & $1.0(1.6)$ & $\mathrm{r}_{\mathrm{s}} 0.420$ \\
\hline & $6(0 ; 20)$ & $4(1 ; 13)$ & $2.0(0 ; 6)$ & $\mathrm{p}<0.001$ \\
\hline \multirow[t]{2}{*}{ Social adaptation (SD) } & $9.6(5.4)$ & $5.1(3.3)$ & $2.7(2.3)$ & $\mathrm{r}_{\mathrm{s}} 0.492$ \\
\hline & $10(0 ; 21)$ & $5(0 ; 12)$ & $2(0 ; 7)$ & $\mathrm{p}<0.001$ \\
\hline
\end{tabular}

Table 4 ESSENCE-Q total score, and subscores, in relation to ICD-10 ASD diagnoses $(n=124)$

\begin{tabular}{|c|c|c|c|c|}
\hline ESSENCE-Q items/Diagnosis & ICD-10 autism $n=89$ & $\begin{array}{l}\text { ICD-10 atypical autism/ } \\
\text { AS } n=17\end{array}$ & $\begin{array}{l}\text { No ICD-10 ASD } \\
\mathrm{n}=18\end{array}$ & $\begin{array}{l}\text { Spearman correla- } \\
\text { tion coefficient \& p } \\
\text { value }\end{array}$ \\
\hline Total score mean (SD) & $11.4(4.9)$ & $6.6(3.0)$ & $4.8(3.2)$ & $\mathrm{r}_{\mathrm{s}} 0.499$ \\
\hline Median (min;max) & $11(2 ; 21)$ & $6(2 ; 12)$ & $4(2 ; 13)$ & $\mathrm{p}<0.001$ \\
\hline \multirow[t]{2}{*}{ General development } & $1.1(0.8)$ & $0.5(0.7)$ & $0.2(0.5)$ & $\mathrm{r}_{\mathrm{s}} 0.412$ \\
\hline & $1.0(0 ; 2)$ & $0.0(0 ; 2)$ & $0.0(0 ; 2)$ & $\mathrm{p}<0.001$ \\
\hline \multirow[t]{2}{*}{ Motor development } & $0.7(0.8)$ & $0.5(0.8)$ & $0.2(0.4)$ & $\mathrm{r}_{\mathrm{s}} 0.202$ \\
\hline & $0.0(0 ; 2)$ & $0.0(0 ; 2)$ & $0.0(0 ; 1)$ & $\mathrm{p}<0.025$ \\
\hline \multirow[t]{2}{*}{ Sensory reactions } & $1.0(0.8)$ & $0.5(0.6)$ & $0.3(0.7)$ & $\mathrm{r}_{\mathrm{s}} 0.312$ \\
\hline & $1.0(0 ; 2)$ & $0.0(0 ; 2)$ & $0.0(0 ; 2)$ & $\mathrm{p}<0.001$ \\
\hline \multirow[t]{2}{*}{ Communication } & $1.4(0.9)$ & $1.1(1.0)$ & $1.4(0.9)$ & $\mathrm{r}_{\mathrm{s}} 0.022$ \\
\hline & $2.0(0 ; 2)$ & $1.0(0 ; 2)$ & $2.0(0 ; 2)$ & $\mathrm{p}<0.805$ \\
\hline \multirow[t]{2}{*}{ Activity } & $1.4(0.8)$ & $0.8(0.9)$ & $0.8(1.0)$ & $\mathrm{r}_{\mathrm{s}} 0.258$ \\
\hline & $2.0(0 ; 2)$ & $0.0(0 ; 2)$ & $0.0(0 ; 2)$ & $\mathrm{p}<0.004$ \\
\hline \multirow[t]{2}{*}{ Attention } & $1.4(0.8)$ & $1.1(0.7)$ & $0.6(0.8)$ & $\mathrm{r}_{\mathrm{s}} 0.328$ \\
\hline & $2.0(0 ; 2)$ & $1.0(0 ; 2)$ & $0.0(0 ; 2)$ & $\mathrm{p}<0.001$ \\
\hline \multirow[t]{2}{*}{ Social interaction } & $1.4(0.8)$ & $0.9(0.8)$ & $0.4(0.6)$ & $\mathrm{r}_{\mathrm{s}} 0.442$ \\
\hline & $2.0(0 ; 2)$ & $1.0(0 ; 2)$ & $0.0(0 ; 2)$ & $\mathrm{p}<0.001$ \\
\hline \multirow[t]{2}{*}{ Behavior } & $0.9(0.9)$ & $0.4(0.7)$ & $0.1(0.5)$ & $\mathrm{r}_{\mathrm{s}} 0.349$ \\
\hline & $1.0(0 ; 2)$ & $0.0(0 ; 2)$ & $0.0(0 ; 2)$ & $\mathrm{p}<0.001$ \\
\hline \multirow[t]{2}{*}{ Mood } & $0.3(0.6)$ & $0.0(0.0)$ & $0.0(0.0)$ & $\mathrm{r}_{\mathrm{s}} 0.233$ \\
\hline & $0.0(0 ; 2)$ & $0.0(0.0)$ & $0.0(0.0)$ & $\mathrm{p}=0.009$ \\
\hline \multirow[t]{2}{*}{ Sleep } & $0.8(0.9)$ & $0.5(0.8)$ & $0.4(0.9)$ & $\mathrm{r}_{\mathrm{s}} 0.156$ \\
\hline & $0.0(0 ; 2)$ & $0.0(0 ; 2)$ & $0.0(0 ; 2)$ & $\mathrm{p}=0.085$ \\
\hline \multirow[t]{2}{*}{ Feeding } & $1.0(0.9)$ & $0.5(0.7)$ & $0.2(0.4)$ & $\mathrm{r}_{\mathrm{s}} 0.375$ \\
\hline & $1.0(0 ; 2)$ & $0.0(0 ; 2)$ & $0.0(0 ; 1)$ & $\mathrm{p}<0.001$ \\
\hline \multirow[t]{2}{*}{ Absences } & $0.2(0.5)$ & $0.0(0.0)$ & $0.1(0.5)$ & $\mathrm{r}_{\mathrm{s}} 0.084$ \\
\hline & $0.0(0 ; 2)$ & $0.0(0.0)$ & $0.0(0.0)$ & $\mathrm{p}=0.356$ \\
\hline
\end{tabular}




\section{CAPRS Total Score and Item Scores}

The ICD-10 Autism group had a mean score on CAPRS that came very close to the $15 \mathrm{p}$ cut-off level for the questionnaire originally proposed by Conners where a clinically significant hyperactivity was likely to be present. All in all, 44 of the 89 individuals (49.4\%) with a diagnosis of ICD-10 Autism scored $\geq 15 p$ on the CAPRS. In contrast, nineteen individuals $(21.3 \%)$ scored $5 p$ or less on the CAPRS questionnaire.

All the items included in the CAPRS items were correlated to the severity of ICD-10 ASD diagnoses. The items Easily frustrated, and Impulsive, were the items with the strongest correlation, and Restless, and Cries often were the items with the weakest correlation towards the ICD-10 ASD diagnoses (Table 5).

\section{Intellectual Ability}

The mean ABC score was significantly correlated to intellectual ability with scores decreasing from the intellectual ability group 3 (IQ 35-49) to the intellectual level group 7 (IQ> 120). However, the ESSENCE-Q, and the CAPRS did not show the same correlation to intellectual ability as did the ABC (Table 6).

\section{Expressive Language Level}

In the ICD-10 Autism group $24.6 \%$ of the individuals were nonverbal or only used single words for communication, $10 \%$ used phrases, $32.6 \%$ was found to use undeveloped sentences, and $32.6 \%$ had adequate speech. For the children belonging to the ICD-10 Atypical autism/AS group the respective percentages were $17.6 \%, 11.8 \%, 17.6 \%$, and $53.0 \%$, and for the No ICD-10 ASD diagnosis group, the same percentages were $16.7 \%, 0 \%, 38.9 \%$, and $44.4 \%$, respectively.

\section{Adaptive Behavior}

All the assessed questionnaires were significantly correlated to Vineland-II GAF mean standard score: CAPRS $\mathrm{r}_{\mathrm{s}} 0.339, \mathrm{p}<0.001$; ESSENCE-Q $\mathrm{r}_{\mathrm{s}} 0.500, \mathrm{p}<0.001$; and $\mathrm{ABC} \mathrm{r}_{\mathrm{s}}$ 0.587, $\mathrm{p}<0.001$. A higher mean score on the questionnaires was correlated to a lower adaptive ability score.
Table 5 CAPRS total score, and subscores, in relation to ICD10 ASD diagnoses $(n=124)$

\begin{tabular}{lclll}
\hline CAPRS/Diagnosis & ICD-10 autism $\mathrm{n}=89$ & $\begin{array}{l}\text { ICD-10 atypical } \\
\text { autism/AS } \mathrm{n}=17\end{array}$ & $\begin{array}{l}\text { No ICD-10 } \\
\text { ASD } n=18\end{array}$ & $\begin{array}{l}\text { Spearman correla- } \\
\text { tion coefficient \& } \mathrm{p} \\
\text { value }\end{array}$ \\
\hline Total score mean (SD) & $13.8(8.6)$ & $8.5(6.4)$ & $6.0(7.5)$ & $\mathrm{r}_{\mathrm{s}} 0.358$ \\
Median (min;max) & $13(0 ; 30)$ & $7(0 ; 23)$ & $2.5(0 ; 23)$ & $\mathrm{p}<0.001$ \\
Restless & $1.8(1.2)$ & $1.2(1.2)$ & $1.2(1.3)$ & $\mathrm{r}_{\mathrm{s}} 0.207$ \\
& $2.0(0 ; 3)$ & $1.0(0 ; 3)$ & $0.5(0 ; 3)$ & $\mathrm{p}=0.021$ \\
Impulsive & $1.6(1.2)$ & $0.8(1.0)$ & $0.6(1.0)$ & $\mathrm{r}_{\mathrm{s}} 0.325$ \\
& $2.0(0 ; 3)$ & $1.0(0 ; 3)$ & $0.0(0 ; 3)$ & $\mathrm{p}<0.001$ \\
Disturbs other & $1.1(1.2)$ & $0.6(0.7)$ & $0.4(0.8)$ & $\mathrm{r}_{\mathrm{s}} 0.255$ \\
Fails to finish tasks & $1.0(0 ; 3)$ & $0.0(0 ; 2)$ & $0.0(0 ; 3)$ & $\mathrm{p}=0.004$ \\
Fidgeting & $1.1(1.2)$ & $1.2(1.2)$ & $0.7(1.0)$ & $\mathrm{r}_{\mathrm{s}} 0.302$ \\
& $2.0(0 ; 3)$ & $1.0(0 ; 3)$ & $0.0(0 ; 3)$ & $\mathrm{p}=0.001$ \\
Inattentive & $1.7(1.2)$ & $0.6(1.0)$ & $0.5(0.8)$ & $\mathrm{r}_{\mathrm{s}} 0.241$ \\
& $1.0(0 ; 3)$ & $0.0(0 ; 3)$ & $0.0(0 ; 2)$ & $\mathrm{p}=0.007$ \\
Easily frustrated & $1.3(1.2)$ & $1.1(1.1)$ & $0.7(1.0)$ & $\mathrm{r}_{\mathrm{s}} 0.248$ \\
Cries often & $1.0(0 ; 3)$ & $1.0(0 ; 3)$ & $0.0(0 ; 3)$ & $\mathrm{p}=0.005$ \\
Memper outbursts & $1.4(1.2)$ & $0.9(1.0)$ & $0.8(1.2)$ & $\mathrm{r}_{\mathrm{s}} 0.342$ \\
& $2.0(0 ; 3)$ & $1.0(0 ; 3)$ & $0.0(0 ; 3)$ & $\mathrm{p}<0.001$ \\
& $1.8(1.1)$ & $0.6(0.9)$ & $0.4(0.9)$ & $\mathrm{r}_{\mathrm{s}} 0.213$ \\
& $1.0(0 ; 3)$ & $0.0(0 ; 3)$ & $0.0(0 ; 3)$ & $\mathrm{p}=0.017$ \\
& $1.1(1.2)$ & $1.1(1.3)$ & $0.4(0.9)$ & $\mathrm{r}_{\mathrm{s}} 0.255$ \\
& $1.0(0 ; 3)$ & $0.0(0 ; 3)$ & $0.0(0 ; 3)$ & $\mathrm{p}=0.004$ \\
& $1.1(1.3)$ & $0.4(0.8)$ & $0.3(0.8)$ & $\mathrm{r}_{\mathrm{s}} 0.271$ \\
& $0.0(0 ; 3)$ & $0.0(0 ; 3)$ & $0.0(0 ; 3)$ & $\mathrm{p}=0.002$ \\
\hline
\end{tabular}


Table 6 ABC, ESSENCE-Q, and CAPRS mean scores, and Vineland-II GAF mean standard score in relation to intellectual ability for all diagnosed participants in the study $(\mathrm{n}=124)$

\begin{tabular}{llllccc}
\hline $\begin{array}{l}\text { Questionnaires/ } \\
\text { Intellectual level* }\end{array}$ & $\begin{array}{l}\text { Intelligence group } \\
\mathrm{n}=4\end{array}$ & $\begin{array}{l}\text { Intelligence group } \\
\mathrm{n}=29\end{array}$ & $\begin{array}{l}\text { Intelligence group } \\
5 \mathrm{n}=42\end{array}$ & $\begin{array}{l}\text { Intelligence group } \\
6 \mathrm{n}=44\end{array}$ & $\begin{array}{l}\text { Intelligence group } \\
7 \mathrm{n}=5\end{array}$ & $\begin{array}{l}\text { Spearman correla- } \\
\text { tion coefficient \& } \mathrm{p} \\
\text { value }\end{array}$ \\
\hline $\mathrm{ABC}$ & $61.0(23.6)$ & $51.0(23.9)$ & $42.1(27.0)$ & $38.6(21.6)$ & $13.8(6.7)$ & $\mathrm{r}_{\mathrm{s}} 0.284$ \\
& $59.5(35 ; 90)$ & $51(10 ; 98)$ & $36.5(2 ; 108)$ & $36.5(7 ; 87)$ & $12(6 ; 24)$ & $\mathrm{p}=0.001$ \\
ESSENCE-Q & $13.5(5.7)$ & $10.1(5.4)$ & $10.4(5.5)$ & $9.4(4.6)$ & $4.2(2.3)$ & $\mathrm{r}_{\mathrm{s}} 0.167$ \\
& $16(5 ; 17)$ & $11(2 ; 19)$ & $10(2 ; 21)$ & $9(2 ; 18)$ & $4(2 ; 8)$ & $\mathrm{p}=0.063$ \\
CAPRS & $12.5(10.7)$ & $10.3(8.9)$ & $12.3(9.1)$ & $13.9(8.0)$ & $5.2(5.8)$ & $\mathrm{r}_{\mathrm{s}} 0.087$ \\
& $10.5(3 ; 26)$ & $7(0,28)$ & $12(0 ; 27)$ & $12.5(0 ; 30)$ & $2(0 ; 14)$ & $\mathrm{p}=0.337$ \\
Vineland-II GAF & $60.8(15.6)$ & $60.6(10.4)$ & $67.4(13.5)$ & $75.7(12.3)$ & $100.2(15.2)$ & $\mathrm{r}_{\mathrm{s}} 0.513$ \\
mean standard & $54(51 ; 84)$ & $59(45 ; 90)$ & $66(47 ; 92)$ & $75(49 ; 105)$ & $105(83 ; 120)$ & $\mathrm{p}<0.001$ \\
score & & & & & \\
\hline
\end{tabular}

*No children qualified for intelligence groups 1 or 2

\section{Discussion}

In this study all the used questionnaires (the $\mathrm{ABC}$, the ESSENCE-Q, and the CAPRS), were found to correlate to the severity of ICD-10 ASD diagnoses, with the highest scores for the group of children with ICD-10 Autism, lower for the group of children with ICD-10 Atypical autism/AS, and lowest for the group of children, who did not receive an ICD-10 ASD diagnosis at the assessment. In addition, all the used questionnaires showed a good correlation across each other.

The ABC mean score correlated to intellectual ability, with the highest mean score for the group of individuals with the lowest intellectual ability as would be expected from earlier research where individuals with an IQ $>70$ were more likely to score below the cut-off for the questionnaire, and hence being falsely judged not having an ASD (e.g., Volkmar et al., 1988; Wadden et al., 1991). The ABC mean score for the participating children was lower than the originally presented cut-off score of 67 points where a diagnosis of Autism is strongly indicated, albeit above the cut-off-scores of $\geq 45 p$ presented by Nordin and Gillberg (1996). However, a large proportion (almost $40 \%$ ) of the individuals diagnosed with an ICD-10 ASD diagnosis in the study had an ABC score even below a cut-off score $\geq 45 p$, which could at least partly be explained by the relatively good intellectual ability present in the assessed group, where the mean IQ for the group was in the so called "Below average" IQ range (i.e., IQ 70-89). In addition, $21.3 \%$ of the children with an ICD10 Autism diagnosis were non-speaking or only used single words for communication with the consequence that the items concerning communication were more likely not to be scored for these children, hence leading to lower total scores on the $\mathrm{ABC}$ for these children. This was in accordance with the findings in the study by Fumagalli Marteleto and Marcondes Pedromonico (2005), and Fernell et al. (2010).
All ABC subscores were correlated to severity in ICD-10 ASD diagnosis. The subscores for Body and Social adaptation displayed the most pronounced correlation, and the subscore for Language showed the weakest correlation, however all subscores presented with a p level of $<0.001$.

In contrast to the ABC, the ESSENCE-Q, and the CAPRS were not significantly correlated to intellectual ability, indicating these questionnaires to be more useful in the evaluation of neuropsychiatric symptoms in children regardless of intellectual ability compared to the $\mathrm{ABC}$.

The results on the ESSENCE-Q were in line with earlier research validating the questionnaire (Gillberg, 2010; Hatakenaka et al., 2016; Stevanovic et al., 2018), where a score of $\geq 3 p$ was considered to indicate a need for further assessment, and only three children (3.4\%) included in this study, who acquired an ICD-10 ASD diagnosis, scored below this cut-off level.

The highest item scores for the ESSENCE-Q were found for Social interaction followed by General development, as would be expected from the clinical perspective. The items Communication, Sleep, and Absences showed no significant difference across the assessed groups. In the case of Соттиnication this might reflect the fact that speech and language problems, which often is a marker for the need for further neuropsychiatric assessment, was the reason for the referring of the child for neuropsychiatric assessment. However, since the children with communication problems, who did not fulfill enough criteria for an ICD-10 ASD diagnosis, ended up in the No ICD-10 ASD diagnosis group, and from there hence conspiring to the absence of a significant correlation across the diagnostic groups concerning the Communication item at the assessment.

Interestingly the CAPRS, which was originally developed as a screening instrument for ADHD, was also correlated to severity in ASD, with higher mean scores for the group of children with ICD-10 Autism compared to both 
the other assessed groups (ICD-10 Atypical autism/AS, and No ICD-10 ASD diagnosis), which speaks in favor of considering early signs such as hyperactivity, and difficulties in finishing tasks, to be more related to autism than to ADHD in pre-school children. The item scores for the CAPRS were all significantly correlated across the ICD-10 ASD diagnoses/No ICD-10 ASD diagnosis groups, albeit from this relatively small material it is not adequate to discuss, which of the items being more ASD or ADHD loaded.

\section{Conclusions}

The result from this study speaks in favor of using all the three assessed questionnaires, the ABC, the ESSENCE-Q, and the CAPRS, in the assessment of pre-school children going through a neurodevelopmental/neuropsychiatric assessment. However, the result from the study confirms previous research data indicating that children with an IQ above 70 often score below the originally validated cut-off levels for the $\mathrm{ABC}$ questionnaire. This must be taken into consideration when deciding to use the $\mathrm{ABC}$ questionnaire, as well as how to interpret the results of the $\mathrm{ABC}$ scoring. The ESSENCE-Q did not show the same correlation to IQ as did the $A B C$, which is preferable in the screening of children with neurodevelopmental/neuropsychiatric problems, and when the proposed cut-off for the questionnaire was used it identified all but three of the children receiving an ICD-10 Autism diagnosis in the study. In addition, the CAPRS, which originally was developed for the assessment of symptoms relating to ADHD, correlated to severity in ICD-10 ASD diagnoses, indicating that symptoms such as hyperactivity, impulsivity and temper tantrums tend to be related to severity of ASD in pre-school children.

\section{Limitations}

Since this is a comparably small study further studies most be performed using the questionnaires to validate if the results from this study are applicable to larger groups of pre-school children with ASD.

Acknowledgments The author wishes to thank all the children and their parent(s)/caregiver(s) for their participation in the study. In addition, the author wishes to thank the neuropsychiatric assessment team at the Child- and Adolescent Clinic at the NU Hospital in Trollhättan, Sweden, and especially speech and language therapist Anda Roman Svantesson.
Funding Open access funding provided by University of Gothenburg. This study was supported by the NU Hospital Group, albeit no funding was received.

\section{Declarations}

Conflict of interest The author declares that he has no conflict of interest.

Ethical approval All procedures performed in studies involving human participants were in accordance with the ethical standards of the institutional and/or national research committee and with the 1964 Helsinki declaration and its later amendments or comparable ethical standards.

Informed Consent The present study was approved by the Human Ethics committee at the Medical Faculty at the University of Gothenburg, Sweden (Dnr 343-14). Informed and signed consent was obtained from all parent(s)/caregiver(s) to the participating children.

Open Access This article is licensed under a Creative Commons Attribution 4.0 International License, which permits use, sharing, adaptation, distribution and reproduction in any medium or format, as long as you give appropriate credit to the original author(s) and the source, provide a link to the Creative Commons licence, and indicate if changes were made. The images or other third party material in this article are included in the article's Creative Commons licence, unless indicated otherwise in a credit line to the material. If material is not included in the article's Creative Commons licence and your intended use is not permitted by statutory regulation or exceeds the permitted use, you will need to obtain permission directly from the copyright holder. To view a copy of this licence, visit http://creativecommons.org/licenses/by/4.0/.

\section{References}

Bayley, N. (2006). Bayley scales of infant and toddler development. (3rd ed.). Pearson.

Broder-Fingert, S., Feinberg, E., \& Silverstein, M. (2018). Improving screening for autism spectrum disorder: Is it time for something new. Pediatrics, 141, e20180965.

Conners, K. (1969). A teacher rating scale for use in drug studies with children. American Journal of Psychiatry, 126, 884-888.

De Giacomo, A., \& Fombonne, E. (1998). Parental recognition of developmental abnormalities in autism. European Child and Adolescent Psychiatry, 7, 131-136.

Fernell, E., Hedvall, A., Norrelgen, F., Eriksson, M., Höglund-Carlsson, L., Barnevik-Olsson, M., Svensson, L., Holm, A., Westerlund, J., \& Gillberg, C. (2010). Developmental profiles in preschool children with Autism Spectrum Disorders referred for intervention. Research in Developmental Disabilities, 31, 790-9.

FumagalliMarteleto, M. R., \& MarcondesPedromonico, M. R. (2005). Validity of Autism Behavior Checklist (ABC): Preliminary study. Brazilian Journal of Psychiatry, 27, 295-301.

Gillberg, C. (2010). The ESSENCE in child psychiatry: Early symptomatic syndromes eliciting neurodevelopmental clinical examinations. Research in Developmental Disabilities, 31, 1543-1551.

Harrington, J. W., \& Allen, K. (2014). The clinician's guide to autism. Pediatrics in Review, 35, 62-78.

Hatakenaka, Y., Fernell, E., Sakaguchi, M., Ninomiya, H., Fukunaga, I., \& Gillberg, C. (2016). ESSENCE-Q-a first clinical validation study of a new screening questionnaire for young children with suspected neurodevelopmental problems in south Japan. Neuropsychiatric Disease and Treatment, 12, 1739-1746. 
Kadesjö, C., Kadesjö, B., Hägglöf, B., \& Gillberg, C. (2001). ADHD in Swedish 3- to 7- year old children. Journal of the American Academy of Child \& Adolescent Psychiatry, 40, 1021-1028.

Krug, D. A., Arick, J., \& Almond, P. (1980). Behavior checklist for identifying severely handicapped individuals with high levels of autistic behaviours. Journal of Child Psychology and Psychiatry, 21, 221-229.

Landis, J. R., \& Koch, G. G. (1977). The measurement of observer agreement for categorical data. Biometrics, 33, 159-174.

Lord, C., Rutter, M., \& LeCouteur, A. (1994). Autism Diagnostic Interview-revised: A revised version of a diagnostic interview for caregivers of individuals with possible pervasive developmental disorders. Journal of Autism and Developmental Disorders, 24, 659-686.

Maljars, M., Noens, I., Scholte, E., \& Berckelaer-Onnes, I. (2012). Evaluation of the criterion and convergent validity of the diagnostic interview for social and communication disorders in young and low functioning children. Autism, 16, 487-497.

Mandell, D. S., Morales, K. H., Xie, M., Lawer, L. J., Stahmer, A. C., \& Marcus, S. C. (2010). Age of diagnosis among medicaidenrolled children with autism, 2001-2004. Psychiatric Service, $61,822-829$.

Neville, B. (2013). Role of ESSENCE for preschool children with neurodevelopmental disorders. Brain and Development, 35, 128-132.

Nordin, V., \& Gillberg, C. (1996). Autism spectrum disorders in children with physical or mental disability or both. II: screening aspects. Developmental Medicine and Child Neurology, 38, 314-324.

Nygren, G., Hagberg, B., Billstedt, E., Skoglund, Å., Gillberg, C., \& Johansson, M. (2009). The Swedish version of the diagnostic interview for social and communication disorders. Psychometric properties. Journal of Autism and Developmental Disorders, 39, 730-741.

Roid, G., \& Sampers, R. (2000). Merrill-Palmer scale revised. (Tryout). Stoelting.

Rowe, K., \& Rowe, K. (1997). Norms for parental rating on conner's abbreviated parent-teacher questionnaire: Implications for the design of behavioral rating inventories and analyses of data derived from them. Journal of Abnormal Child Psychology, 25, 425-451.

Ryan, S., \& Salisbury, H. (2012). "You know what boys are like": Prediagnosis experiences of parents of children with autism spectrum conditions. British Journal of General Practice, 62, e378-e383.

Sparrow, S., Cicchetti, D., \& Balla, D. (2005). Vineland Adaptive Behavior Scales. (2nd ed.). Minneapolis: NCS Pearson Inc.

Stevanovic, D., Knez, R., Zorcec, T., Anderluh, M., Kodriĉ, J., Petrov, P., HadžagićĆatibušić, F., Deljković, A., BrkicSvetkovic, S., VrljičakDavidovic, N., KuzmanićŠamija, R., Đorić, A.,
\& Gillberg, C. (2018). ESSENCE-Q: Slavic language versions for developmental screening in young children. Neuropsychiatric Disease and Treatment, 14, 2141-2148.

Volkmar, F., Cichetti, D., Dykens, E., Sparrow, S., Leckman, J., \& Cohen, D. (1988). An evaluation of the Autism Behavior Checklist. Journal of Autism and Developmental Disorders, 18, 81-97.

Wadden, N. P. K., Bryson, S., \& Rodger, R. (1991). A closer look at the Autism Behavior Checklist: Discriminant validity and factor structure. Journal of Autism and Developmental Disorders, 21, $529-541$.

Wechsler, D. (2002). Wechsler preschool and primary scale of intelligence. (3rd ed.). The Psychological Corporation.

Wechsler, D. (2003). Wechsler intelligence scale for children. (4th ed.). Pearson.

Wechsler, D. (2012). Wechsler preschool and primary scale of intelligence. (4th ed.). Pearson.

Wechsler, D., \& Naglieri, J. A. (2006). Wechsler nonverbal scale of ability. San Antonio: Pearson.

Wimpory, D. C., Hobson, R. P., Williams, J. M., \& Nash, S. (2000). Are infants with autism socially engaged? A study of recent retrospective parental reports. Journal of Autism and Developmental Disorders, 30, 525-536.

Wing, L. (2006). Diagnostic interview for social and communication disorders. (11th ed.). Bromley: Centre for Social and Communication Disorders.

Wing, L., Leekam, S. R., Libby, S. J., Gould, J., \& Larcombe, M. (2002). The Diagnostic interview for social and communication disorders: Background, inter-rater reliability and clinical use. Journal of Child Psychology and Psychiatry, 43, 307-325.

World Health Organization. (1992). Manual of the International statistical classification of diseases, and related health problems-Tenth Revision. World Health Organisation.

Zablotsky, B., Black, L., Maenner, M. J., Schieve, L. A., \& Blumberg, S. J. (2015). Estimated prevalence of autism and other developmental disabilities following questionnaire changes in the 2014 national health interview survey. National Health Statistical Report, 13(87), 1-20.

Zwaigenbaum, L., Bryson, S., Brian, J., Smith, I. M., Roberts, W., Szatmare, P., Roncadin, C., Gaaron, N., \& Vaillancourt, T. (2016). Stability of diagnostic assessment for autism spectrum disorder between 18 and 36 months in a high-risk cohort. Autism Research, 9, 790-800.

Publisher's Note Springer Nature remains neutral with regard to jurisdictional claims in published maps and institutional affiliations. 